\title{
Healthcare Communication - by Bruce Hugman: Review
}

Ed: Bruce Hugman; Pharmaceutical Press, London, UK, 2009

Hugman's Healthcare Communication is a rare gem that engages its readers and explores healthcare communication beyond uni-professional boundaries. Bruce Hugman has worked previously with the World Health Organization as a communications consultant in the areas of pharmacovigilance and patient safety. Apart from his involvement in the UN, Hugman has taught, managed, and represented on an international level. Consequently, many of the examples in this text come from his experiences and world views. Although he is not, nor has ever been a healthcare professional, he has a sound understanding of health care systems and the issues they face.

Hugman's purpose in writing this book is to motivate and challenge everyone- whether maintenance personnel, nurse, pharmacist, or doctor - within the healthcare system to communicate effectively as a service to his or herself and to healthcare as a whole. The author strongly believes that having an "accurate insight into what life is really like for other people transforms how we see the world, and how we think, feel, behave and communicate." On the other hand, Hugman also advocates that understanding ourselves allows us to tailor what we say and how we react so that we may communicate with our patients objectively and sincerely.

The introduction reveals the intent and purpose of the book, and gives you a guide for how to approach reading the book based on both time and area of INTEREST. A "basic skeleton framework" is provided for encounters between health care professionals and patients. The framework highlights key issues, attitudes, knowledge and skills required for effective communication. While pharmacist specific approaches are would be required for pharmacist training, this framework outlines the commonalities of communication in the health care team.

The text is divided into eight main parts. Hugman begins by looking at the importance of communication, the purpose of healthcare, and the value of self awareness. With this foundation, he moves into effective communication skills, understanding humanity, and cooperation within a healthcare team. The chapter on risk communication is an exceptional review of practical steps which would enhance all pharmacists' ability to support their patients in decision making. Next, the author addresses the "Tough Topics." From sexuality to death, Hugman explores challenging situations that are faced everyday in community health facilities or in places like the ER. He offers practical solutions and suggestions in how to handle these difficult situations with the use of effective communication skills. Last, the author looks at the "broader communications picture" and dives into the various methods and styles of communications, whether it is an email, phone call, or public presentation. Examples used in the book are very relevant, such as use of Wikipedia, email or SMS. Hugman helps his readers find ways to handle complaints, collaborate with other HCP's, learn from patient dissatisfaction, and mange meeting effectively.

The author encourages self reflection throughout the book and provides exercises at the end of each of the nine parts which stimulate revision, discussion and application. The questions and ideas presented would allow learners to explore how communication topics can be applied in their own settings. On top of the useful tips and intriguing information found within this text, the appendices also include a summary of the oft cited Calgary-Cambridge consultation framework. This detailed supplement to the "basic skeleton framework" outlined in the beginning of the book elaborates on the communication skills required for effective communication.

Healthcare Communication provides its readers with exploratory thought and discussion that will leave one with plenty to ponder and the tools to do so. Though optimistic, the author uses a realistic approach as he recognizes the barriers and limitations of implementing new communication models, such as finance and time. The book is easyto-read with text, example boxes, original cartoons, and case studies. With quotes ranging from Shirley Temple to Friedrich Nietzsche, Hugman adds a creative flavor to this already appealing healthcare text.

There are two items to note in Hugman's book. While this book is based on sound evidence and 
theoretical foundation, the author incorporates personal views and experience. It is sometimes hard to differentiate between the author's personal beliefs and the universal neutrality he is pursuing. Some readers may struggle with his stance on certain ethical issues. However, there are ample resources provided throughout the book that would allow the reader to form his or her own opinion. Second, despite the healthcare team focus, some topics are discussed with a focus on an individual healthcare profession, often physicians.

As a whole, this text would be an enriching addition to a pharmacy curriculum and allow for communication to be placed in the broader context of the health care system. This book does not read like a traditional textbook and as such would be an accessible supplement to a practicing healthcare professional's library.

The book has 320 pages and is modestly priced at approximately $\$ 50$.

Lisa Guirguis, BSc(Pharm), MSc, PhD, lguirguis@pharmacy.ualberta.ca, Ashley Young and Vanessa Butt Faculty of Pharmacy and Pharmaceutical Sciences University of Alberta, Edmonton, Alberta, Canada. 